\title{
Correction to: Comparison of Single-Phase and Two-Phase Composite Thermal Barrier Coatings with Equal Total Rare-Earth Content
}

\author{
Amarendra K. Rai ${ }^{1}$ - Michael P. Schmitt ${ }^{2}$ - Mitchell R. Dorfman ${ }^{3}$. \\ Dongming $\mathrm{Zhu}^{4} \cdot$ Douglas E. Wolfe ${ }^{5,6}$
}

Published online: 3 August 2018

(C) ASM International 2018

Correction to: J Therm Spray Tech (2018) 27:556 https://doi.org/10.1007/s11666-018-0713-3

Addendum is for Figure 8 caption.

Current caption: Thermal cycling results for samples tested at $1150{ }^{\circ} \mathrm{C}$ for $60 \mathrm{~min}$, followed by 10 -min fan cooling. Results indicate that the single-phase sample has the best thermal cyclic life, while the spray-dried coating exhibits a lower lifetime.

Correct caption: Thermal cycling results for samples tested at $1150{ }^{\circ} \mathrm{C}$ for $50 \mathrm{~min}$, followed by 10 -min fan cooling. Results indicate that the single-phase spray-dried sample has the best thermal cyclic life, while the two-phase core-clad coating exhibits a lower lifetime.

The original article can be found online at https://doi.org/10.1007/ s11666-018-0713-3.

Michael P. Schmitt

m.schmitt@hamrindustries.com

1 UES, Inc., 4401 Dayton-Xenia Road, Dayton, OH 45432, USA

2 HAMR Industries LLC, 1315 W College Avenue, State College, PA 16801, USA

3 Oerlikon Metco, Danbury, NY, USA

$4 \quad$ NASA Glenn Research Center, Cleveland, OH 44135, USA

5 Materials Science and Engineering Department and the Applied Research Laboratory, The Pennsylvania State University, University Park, PA 16802, USA

6 Engineering Science and Mechanics Department, The Pennsylvania State University, University Park, PA 16802, USA 